(C) by Oldenbourg Wissenschaftsverlag, München

\title{
Crystal structure of disamarium undecaoxotetratellurate(IV), $\mathrm{Sm}_{2} \mathrm{Te}_{4} \mathrm{O}_{11}$
}

\author{
K. Sugiyama ${ }^{*, I}$, R. Simura' and B. Wedel ${ }^{\text {II }}$ \\ I University of Tokyo, Graduate School of Science, Department of Earth and Planetary Science, Hongo 7-3-1, Bunkyo-ku, Tokyo, 113-0033 Japan \\ II Tohoku University, Institute for Multidisciplinary Research, Katahira 2-1-1, Aoba-Ku, Sendai, 980-8577 Japan
}

Received March 28, 2005, accepted and available on-line April 25, 2005; CSD no. 409823

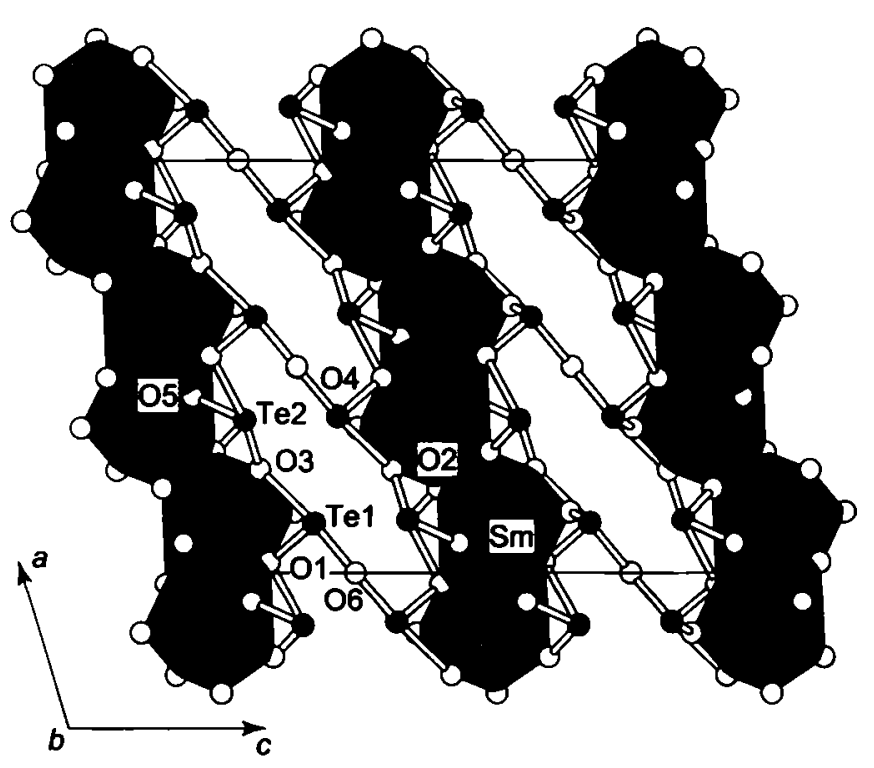

\section{Abstract}

$\mathrm{O}_{11} \mathrm{Sm}_{2} \mathrm{Te}_{4}$, monoclinic, $C 12 / c 1$ (no. 15),

$a=12.569(1) \AA, b=5.1790(7) \AA, c=16.211(2) \AA$,

$\beta=106.040(6)^{\circ}, V=1014.2 \AA^{3}, Z=4$,

$R_{\mathrm{gt}}(F)=0.035, w R_{\text {ref }}\left(F^{2}\right)=0.078, T=298 \mathrm{~K}$.

\section{Source of material}

Single crystals of $\mathrm{Sm}_{2} \mathrm{Te}_{4} \mathrm{O}_{11}$ were prepared from the reaction of $\mathrm{Sm}_{2} \mathrm{O}_{3}$ (Kojyundo Kagaku Co. Ltd.) and $\mathrm{TeO}_{2}$ (Wako Chemical Co. Ltd.). The starting mixture of $\mathrm{Sm}_{2} \mathrm{O}_{3}$ and $\mathrm{TeO}_{2}$ with a molar ratio of 1:4 was pressed into a shape of pellet and subsequently heated at $1073 \mathrm{~K}$ for two days in an $\mathrm{Al}_{2} \mathrm{O}_{3}$ crucible.

\section{Discussion}

$\mathrm{Sm}_{2} \mathrm{Te}_{4} \mathrm{O}_{11}$ is isostructural with $L n_{2} \mathrm{Te}_{4} \mathrm{O}_{11}(L n=\mathrm{La}-\mathrm{Lu})[1,2]$. Detailed structural features were reported in the single crystal studies for $\mathrm{Pr}_{2} \mathrm{Te}_{4} \mathrm{O}_{11}$ [3], $\mathrm{Nd}_{2} \mathrm{Te}_{4} \mathrm{O}_{11}$ [4], $\mathrm{Ho}_{2} \mathrm{Te}_{4} \mathrm{O}_{11}$ [5] and $\mathrm{Er}_{2} \mathrm{Te}_{4} \mathrm{O}_{11}$ [6]. The $\mathrm{SmO}_{8}$ coordination polyhedron shows a distorted square antiprism, so as to form a polyhedral sheet parallel to the (001) plane. The $\mathrm{Sm}-\mathrm{O}$ distances range from $2.335(5) \AA$ to $2.580(5) \AA$. The averaged distance of $2.437 \AA$ in the $\mathrm{SmO}_{8}$ coordination is comparable with those for $\mathrm{Pr}-\mathrm{O}(2.473 \AA), \mathrm{Nd}-\mathrm{O}$ $(2.460 \AA), \mathrm{Ho}-\mathrm{O}(2.379 \AA)$ and $\mathrm{Er}-\mathrm{O}(2.364 \AA)$, when the lanthanoide contraction is considered. Tel is coordinated to three shorter distances of 1.831(4) $\AA, 1.883(4) \AA$ and $1.996(2) \AA$ and a longer distance at $2.406(5) \AA$. Similar coordination feature was observed in the Te2 environment with the distances of 1.869 (4) $\AA$, $1.870(5) \AA, 1.887(5) \AA$ and $2.673(5) \AA$. The $\mathrm{TeO}_{4}$ polyhedra are linked by sharing their corners to form the 'lone pair miscell' running parallel to the $b$ axis. The bond valence calculation [7] supports the coordination of $\mathrm{Te}$ (IV) in the title compound.

Table 1. Data collection and handling.

\begin{tabular}{ll}
\hline Crystal: & $\begin{array}{l}\text { pale yellow block, } \\
\text { size } 0.05 \times 0.05 \times 0.07 \mathrm{~mm}\end{array}$ \\
Wavelength: & Mo $K_{\alpha}$ radiation $(0.71069 \AA)$ \\
$\mu$ : & $227.96 \mathrm{~cm}^{-1}$ \\
Diffractometer, scan mode: & Rigaku R-AXIS RAPID IP, $\omega / \varphi$ \\
$2 \theta_{\text {max }}:$ & $60.9^{\circ}$ \\
$N(h k l)_{\text {measured, }} N(h k l)_{\text {unique: }}:$ & 5590,1538 \\
Criterion for $I_{\text {obs, }} N(h k l)_{\text {gi }}:$ & $I_{\text {obs }}>2 \sigma\left(I_{\text {obs }}\right), 1117$ \\
$N(\text { param })_{\text {refined: }}$ & 79 \\
Programs: & SHELXL-97 [8], ATOMS [9]
\end{tabular}

Table 2. Atomic coordinates and displacement parameters (in $\AA^{2}$ ).

\begin{tabular}{|c|c|c|c|c|c|c|c|c|c|c|}
\hline Atom & Site & $x$ & $y$ & $z$ & $U_{11}$ & $U_{22}$ & $U_{33}$ & $U_{12}$ & $U_{13}$ & $U_{23}$ \\
\hline Sm & $8 f$ & $0.11878(3)$ & $0.24586(6)$ & $0.53723(2)$ & $0.0068(2)$ & $0.0072(2)$ & $0.0081(2)$ & $0.0000(2)$ & $0.0026(1)$ & $0.0001(1)$ \\
\hline $\operatorname{Te}(1)$ & $8 f$ & $0.12052(4)$ & $0.2266(1)$ & $0.20161(3)$ & $0.0084(2)$ & $0.0090(2)$ & $0.0079(2)$ & $-0.0015(2)$ & $0.0009(2)$ & $0.0009(1)$ \\
\hline $\mathrm{Te}(2)$ & $8 f$ & $0.37091(3)$ & $0.2792(1)$ & $0.12768(2)$ & $0.0066(2)$ & $0.0073(2)$ & $0.0070(2)$ & $-0.0000(2)$ & $0.0020(2)$ & $-0.0004(1)$ \\
\hline$O(1)$ & $8 f$ & $0.0267(4)$ & $0.0911(9)$ & $0.0995(3)$ & $0.007(2)$ & $0.012(2)$ & $0.011(2)$ & $-0.004(2)$ & $0.001(2)$ & $-0.006(2)$ \\
\hline $\mathrm{O}(2)$ & $8 f$ & $0.2061(4)$ & $0.0410(9)$ & $0.4435(3)$ & $0.013(3)$ & $0.011(2)$ & $0.011(2)$ & $-0.006(2)$ & $0.005(2)$ & $-0.008(2)$ \\
\hline$O(3)$ & $8 f$ & $0.2502(4)$ & $0.0646(8)$ & $0.1293(3)$ & $0.010(2)$ & $0.011(2)$ & $0.011(2)$ & $-0.005(2)$ & $0.003(2)$ & $-0.003(2)$ \\
\hline$O(4)$ & $8 f$ & $0.3520(4)$ & $0.0551(9)$ & $0.3290(3)$ & $0.018(3)$ & $0.011(2)$ & $0.007(2)$ & $0.004(2)$ & $0.004(2)$ & $0.000(2)$ \\
\hline$O(5)$ & $8 f$ & $0.4283(4)$ & $0.1185(9)$ & $0.0460(3)$ & $0.009(2)$ & $0.011(2)$ & $0.014(2)$ & $-0.002(2)$ & $0.002(2)$ & $-0.005(2)$ \\
\hline$O(6)$ & $4 e$ & 0 & $0.351(1)$ & $1 / 4$ & $0.016(4)$ & $0.016(3)$ & $0.017(3)$ & 0 & $0.012(3)$ & $\mathbf{0}$ \\
\hline
\end{tabular}

\footnotetext{
* Correspondence author (e-mail: kazumasa@eps.s.u-tokyo.ac.jp)
} 
Acknowledgments. The authors gratefully acknowledge the financial support of Grant-in-Aid for Scientific Research (B) (grant no. 14340161) from The Ministry of Education, Culture, Sports, Science and Technology (MEXT).

\section{References}

1. Redman, M. J.; Binnie, W. P.; Carter, J. R.: Compound formation in the systems rear-earth oxides-tellurium dioxide. J. Less-Common Met. 16 (1968) 407-413.

2. Lopez, M. L.; Veiga, M. L.; Fernandez, F.; Jerez, A.; Pico, C.: Synthesis, characterization and magnetic properties of $L n_{2} \mathrm{Te}_{4} \mathrm{O}_{11}(L n=\mathrm{La}, \mathrm{Nd}, \mathrm{Sm}$, Eu, Gd, and Ho). J. Less-Common Met. 166 (1990) 367-375.

3. Ijjaali, I.; Flaschenriem, C.; Ibers, J. A.: Synthesis and characterization of the wide band-gap compound $\operatorname{Pr}_{2} \mathrm{Te}_{4} \mathrm{O}_{11}$. J. Alloys Comp. 354 (2003) 115-119.
4. Castro, A.; Enialbert, R.; Lloyd, D.; Rasines, I.; Galy, J.: Crystal Structure of $\mathrm{Nd}_{2} \mathrm{Te}_{4} \mathrm{O}_{11}$ : An Example of a Rear Earth Tellurium Oxide. J. Solid State Chem. 85 (1990) 100-107.

5. Weber, F. A.; Meier, S. F.; Schleid, T.: $\mathrm{Ho}_{2} \mathrm{Te}_{4} \mathrm{O}_{11}$ und $\mathrm{Ho}_{2} \mathrm{Te}_{5} \mathrm{O}_{13}$ : Zwei tellurdioxidreiche Oxotellurate(IV) des dreiwertigen Holmiums. $Z$. Anorg. Allg. Chem. 627 (2001) 2225-2231 .

6. Shen, Y.-L.; Mao, J.-G.: Synthesis, crystal structure and luminescent properties of $\mathrm{Er}_{2} \mathrm{Te}_{4} \mathrm{O}_{11}$. J. Alloys Comp. 385 (2004) 86-89.

7. Brown, I. D.; Altermatt, D.: Bond-Valence Parameters obtained from a Systematic Analysis of the Inorganic Crystal Structure Database. Acta Crystallogr. B41 (1985) 244-247.

8. Sheldrick, G. M.: SHELXL-97. Program for the Refinement of Crystal Structures. University of Göttingen, Germany 1997.

9. Dowty, E.: ATOMS. A Computer Program for Displaying Atomic Structures. Version 6.1. Shape Software, Kingsport, Tennessee, USA 2004 